\title{
Influence of dosage, storage time and temperature on efficacy of metalaxyl-treated seed for the control of pearl millet downy mildew
}

\author{
Ram P. Thakur • Veeranki P. Rao • Rajan Sharma
}

Accepted: 23 August 2010 / Published online: 9 September 2010

(C) KNPV 2010

\begin{abstract}
Metalaxyl (Apron 35WS) as a seed treatment has been used extensively to control downy mildew (caused by Sclerospora graminicola) in pearl millet in India. However, the extent of disease control has varied across cultivars, years and locations. We investigated the effects of fungicide dosage, storage time and storage temperature of metalaxyl-treated seed on disease incidence in four pearl millet lines having varying levels of resistance. A linear relationship was found between fungicide dosage $(0.5,1.5$ and $2 \mathrm{~g}$ a.i. $\mathrm{kg}^{-1}$ seed) and reduction in disease incidence up to 40 days after emergence in all the lines. The normal fungicide dose $\left(2 \mathrm{~g}\right.$ a.i. $\mathrm{kg}^{-1}$ seed $)$ protected the crop for up to 20,40 and 50 days after emergence in highly susceptible (7042S), moderately susceptible (4042R), and moderately resistant (ICMP 451) lines, respectively. However, the quarter and half the normal dosage of fungicide provided protection only up to 20 days after emergence in $7042 \mathrm{R}$ and 40 days after emergence in ICMP 451. Storage duration of metalaxyl-treated seed $\left(2 \mathrm{~g}\right.$ a.i. $\left.\mathrm{kg}^{-1}\right)$ up to 9 months at $25 \pm 2{ }^{\circ} \mathrm{C}$ did not affect fungicide efficacy. Storage temperatures $\left(5,25\right.$ and $\left.40^{\circ} \mathrm{C}\right)$ and duration $(30,60$ and 90 days) of metalaxyl-treated seed $\left(2 \mathrm{~g}\right.$ a.i. $\left.\mathrm{kg}^{-1}\right)$ showed differential effects in two
\end{abstract}

R. P. Thakur $(\bowtie) \cdot$ V. P. Rao $\cdot$ R. Sharma International Crops Research Institute for the Semi-Arid Tropics,

Patancheru 502324 Andhra Pradesh, India

e-mail: r.thakur@cgiar.org pearl millet lines $7042 \mathrm{~S}$ and $843 \mathrm{~B}$ with downy mildew incidence being significantly lower in $7042 \mathrm{~S}$ than in 843B. Metalaxyl-treated seed of $7042 \mathrm{~S}$ and $843 \mathrm{~B}$ stored at $40^{\circ} \mathrm{C}$ for different durations showed phytotoxic effects and it was more pronounced in 843B stored for 60 and 90 days where seed germination was inhibited in pot soil.

Keywords Metalaxyl · Pearl millet · Sclerospora graminicola $\cdot$ Storage time $\cdot$ Temperature

\section{Introduction}

Downy mildew disease of pearl millet [Pennisetum glaucum (L.) R. Br.] caused by the obligate parasite Sclerospora graminicola (Sacc.) Schroet is widespread and economically important in India and several countries in Africa. The disease can be best managed through host-plant resistance. Several breeding lines, hybrids and open-pollinated varieties (OPVs) having downy mildew resistance have been developed (Talukdar et al. 1999; Hash et al. 1999; Thakur et al. 2001). In India, the disease is particularly serious on single-cross $F_{1}$ hybrids than on OPVs. This is due to a narrow genetic base and uniformity of the hybrids than those of OPVs that are highly heterogeneous. During the past 25 years there has been steady growth in the number of hybrids and area under hybrid cultivation in India. Currently, about $50 \%$ of the 9 million ha under pearl millet cultivation 
is grown with over 70 different single-cross hybrids in India (Rai et al. 2006). Downy mildew incidence has been quite variable on different hybrids and more than $90 \%$ incidence has been recorded on some hybrids in farmers' fields (Thakur et al. 2003; Rao et al. 2007). The estimated annual grain yield loss due to downy mildew is approximately 20 to 40\% (Singh 1995; Hash et al. 1999; Hess et al. 2002) but this could be much higher under favorable conditions of disease development (Singh 1995; Thakur 1998, 2008). In addition to host-plant resistance, seed treatment with metalaxyl-based fungicide (Apron 35WS) has been found effective in managing downy mildews in pearl millet (Williams and Singh 1981; Singh et al. 1984; Singh and Shetty 1990) and other crops (Gisi and Sierotzki 2008; Thind 2008). Metalaxyl (Apron ${ }^{\circledR}$ ), a phenylamide class of fungicide that inhibits ribosomal RNA synthesis, has been formulated as $35 \%$ WS for application as a dust or slurry to seed to control downy mildews in many crops, including pearl millet, sorghum and maize (CIBA-GEIGY Technical Product Information-3, 1989). Metalaxyl penetrates the seed coat and is systemically translocated to both shoots and roots during germination (Thind 2008). Seed treatment by metalaxyl protects the young plants from systemic primary infection and secondary infection during the early growth period for up to four weeks (Williams and Singh 1981; Singh and Shetty 1990). This normally helps prevent epidemics of downy mildews in graminaceous crops.

In India, most seed companies treat pearl millet hybrid seed with metalaxyl before marketing to farmers (Thakur et al. 2003; Rao et al. 2007). Private seed companies spend about US \$1.8 million per year to treat pearl millet seed with metalaxyl (pers. Communication). This level of phenylamide fungicide use is insignificant compared to that used for controlling diseases caused by oomycetes on grapes, cucurbits, lettuce, onion and tobacco (Gisi and Sierotzki 2008). However, this treatment is effective only with moderately resistant hybrids in certain environments. The fungicide is not effective with susceptible hybrids, which are protected only up to 40 days after emergence and the disease appears on nodal tillers and as "green ear" at the later stages of crop growth. The cost of treated seed is about $10 \%$ higher than untreated seed and farmers have to pay the additional price without any assurance of protection from the disease. Also, currently no such regulation exists in India under which the concerned seed companies can compensate farmers for crop loss. This chemical approach to downy mildew management may also lead to the emergence of fungicide resistant biotypes.

In India, with increasing land area under hybrid cultivation since the 1970s downy mildew has become more severe and more widespread (Thakur et al. 2006). The most cost-effective management of the disease can be obtained by breeding downy mildew-resistant pearl millet hybrids. There has been considerable success in breeding for downy mildew resistance using conventional pedigree breeding, and a large number of disease resistant hybrids have been developed and deployed (Khairwal et al. 2004). This has contributed to management of widespread downy mildew epidemics since the 1990s (Thakur et al. 2006). Marker-assisted backcross breeding has further enhanced the ability and efficiency of downy mildew resistance breeding (Hospital et al. 1992; Hash et al. 1999; Hash and Witcombe 2002). However, in view of the increasing severity of the disease and evolution of new more virulent pathotypes (Thakur et al. 2004) there is a need to develop a long-term strategy for downy mildew management. In order to optimize the use of metalaxyl we investigated the effects of different dosages, storage duration and storage temperature of treated seed on downy mildew incidence in pearl millet lines.

\section{Materials and methods}

Metalaxyl concentration

Seed of a highly susceptible pearl millet line 7042S and two moderately resistant lines 7042R and ICMP451 were treated with four concentrations of metalaxyl (Apron 35 WS) $\left(0.5,1.0,1.5\right.$ and $2.0 \mathrm{~g}$ a.i. $\mathrm{kg}^{-1}$ seed). Treated seed was sown in the downy mildew plot infested with $S$. graminicola oospores along with the untreated control. In addition to oospore inoculum in the infested plot, infector rows of the susceptible line 7042S were grown after every four rows as inoculum donor though asexual spores (Singh et al. 1993). The experiment was conducted in a randomized complete block design (RCBD) with 2 rows of $4 \mathrm{~m}$ length and 3 replications. Disease incidence was recorded at 10, 20, 30, 40, 50 and 60 days after emergence. 
Storage time

Seed of three lines (7042S, 7042R and ICMP 451) were treated with metalaxyl $\left(2 \mathrm{~g}\right.$ a.i. $\mathrm{kg}^{-1}$ seed $)$ and stored for 0 (fresh seed treatment) to up to 9 months at laboratory temperature $\left(25 \pm 2^{\circ} \mathrm{C}\right)$. The experiment was conducted in a RCBD with 9 storage periods as treatments and 6 replications, 4 rows of $2 \mathrm{~m}$ long/ replication. Downy mildew incidence was recorded at 10 day-intervals after seedling emergence up to 70 days.
Storage temperature

Metalaxyl-treated seed ( $2 \mathrm{~g}$ a.i. $\mathrm{kg}^{-1}$ ) lots of two susceptible lines $7042 \mathrm{~S}$ and $843 \mathrm{~B}$ were stored in incubators at 5,25 and $40^{\circ} \mathrm{C}$ for 3 months in darkness. An experiment with six treatments $(2$ lines $\times 3$ storage temperatures) with three replications using a completely randomized design (CRD) was conducted in the greenhouse. Seed were sown in pots filled with autoclaved potting mixture soil, sand and farm yard manure (2:1:1 by volume) and 30-35 seedlings were
Fig. 1 Effect of different dosages of metalaxyl (Apron 35WS) treatment on downy mildew incidence in three pearl millet lines (7042S, 7042R and ICMP 451) in a field experiment

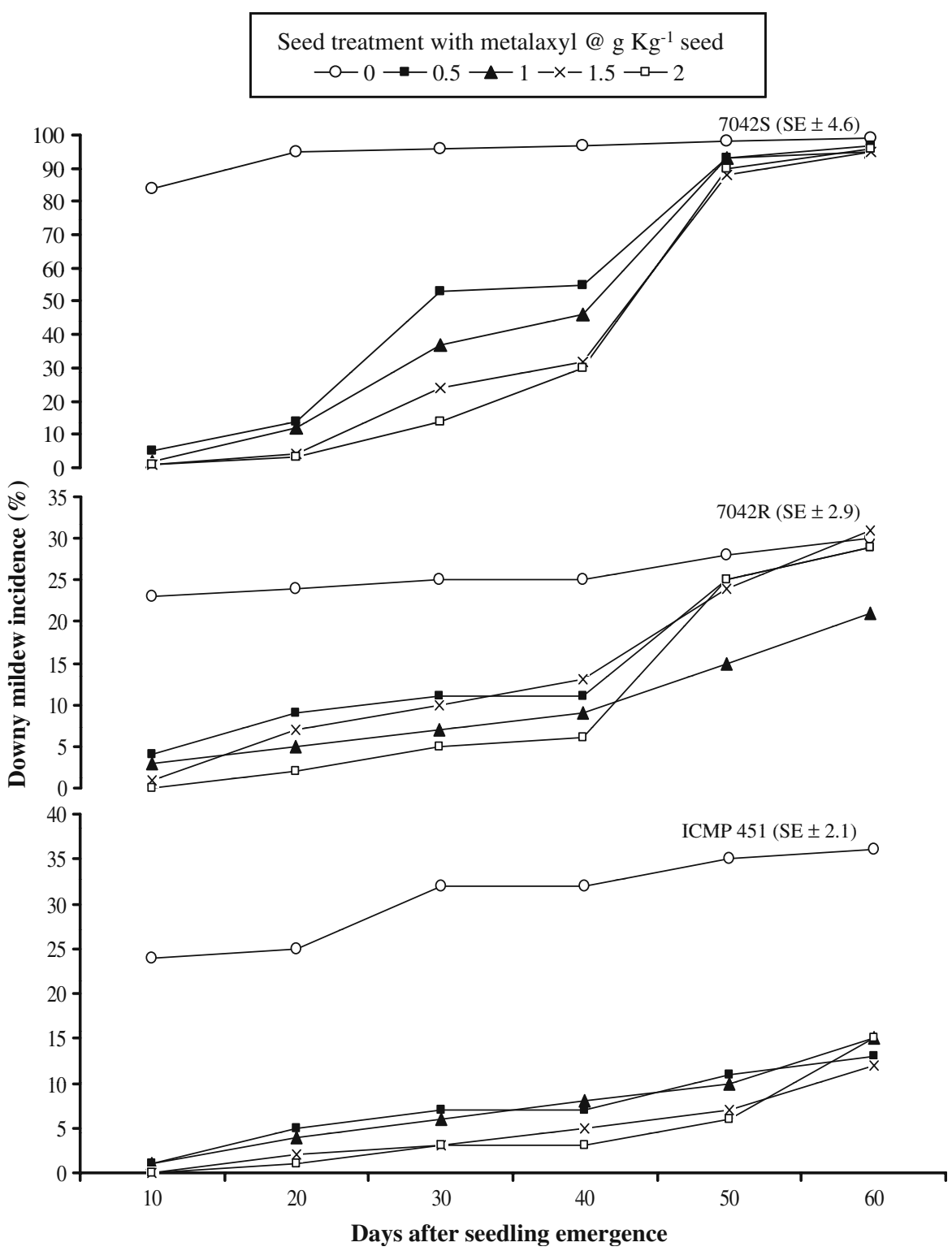


maintained in each pot. Seedlings at the 2-leaf stage were spray inoculated with a sporangial suspension $\left(1 \times 10^{5}\right.$ sporangia $\mathrm{ml}^{-1}$ ) of Patancheru isolate of $S$. graminicola (Sg 409). Downy mildew incidence was recorded two weeks after inoculation.

\section{Results}

Effect of metalaxyl concentration

Metalaxyl seed treatment provided protection from downy mildew ( $<10 \%$ incidence) up to 10 days after emergence to the highly susceptible line $7042 \mathrm{~S}$ at all four concentrations compared to $84 \%$ incidence in the control (no fungicide treatment). At concentrations of 1.5 and $2.0 \mathrm{~g}$ a.i. metalaxyl $\mathrm{kg}^{-1}$ seed protection duration increased up to 25 days, but by 60 days disease incidence increased to above $80 \%$ in all concentrations indicating that fungicide was not effective 25 days after emergence in $7042 \mathrm{~S}$ (Fig. 1). In moderately resistant lines $7042 \mathrm{R}$ and ICMP 451 protection from downy mildew occurred up to 40 and 50 days after seedling emergence, respectively, in treated seed at all concentrations. Downy mildew incidence increased rapidly after 40 days in $7042 \mathrm{R}$ to reach $25 \%$ while it increased slowly in ICMP 451 and reached $12 \%$ by 60 days. No significant differences were observed for downy mildew incidence in ICMP 451 with metalaxyl concentrations. Therefore, reducing the fungicide concentration to half $\left(1.0 \mathrm{~g}\right.$ a.i. $\mathrm{kg}^{-1}$ seed) the recommended dose $\left(2 \mathrm{~g}\right.$ a.i. $\mathrm{kg}^{-1}{ }^{1}$ seed $)$ may effectively control the disease in moderately resistant cultivars.
Fig. 2 Effect of storage duration of metalaxyl (Apron $35 \mathrm{WS}$ )-treated seed on downy mildew incidence of three pearl millet lines (7042S, 7042R and ICMP 451) in a field experiment

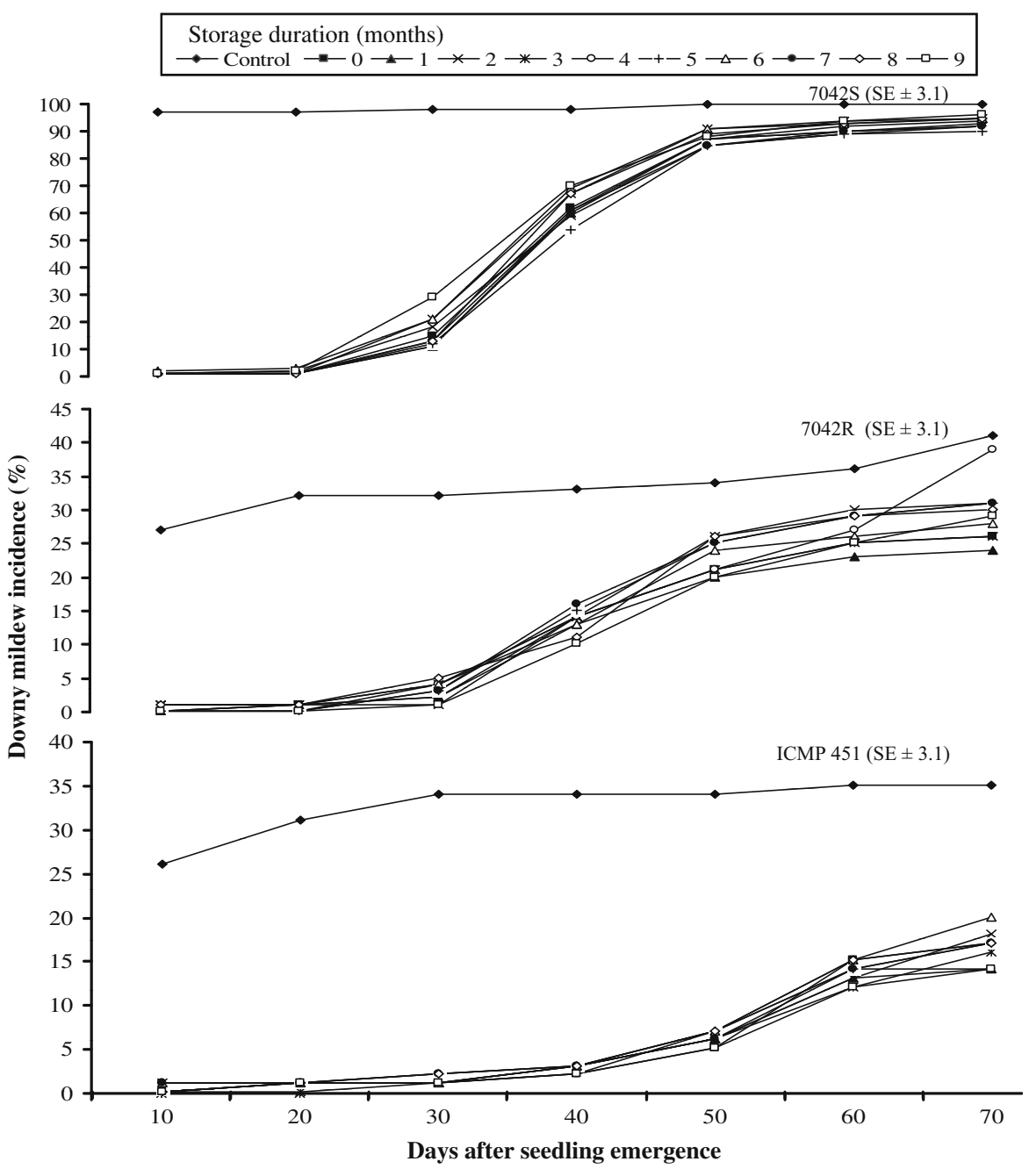


Effect of storage duration

Metalaxyl treatment protected seedlings from downy mildew ( $<10 \%$ incidence) for up to 20 days in $7042 \mathrm{~S}$, 30 days in $7042 \mathrm{R}$ and 50 days in ICMP 451, irrespective of storage durations of treated seed (Fig. 2). The results indicate that storage duration of treated seed up to 9 months does not affect the efficacy of metalaxyl seed treatment. However, protection was longer in the moderately resistant line than in the highly susceptible line as reported above.

\section{Effect of storage temperature}

Storage temperatures of treated seed did not influence effectiveness of fungicide in reducing downy mildew incidence. Downy mildew incidence ranged from 0 to $38 \%$ in fungicide-treated seed compared to 60 to $100 \%$ in untreated controls in two pearl millet lines $7042 \mathrm{~S}$ and $843 \mathrm{~B}$ up to 90 days of crop growth (Fig. 3). In
843B, however, metalaxyl-treated seed stored at $40^{\circ} \mathrm{C}$ for 60 and 90 days did not emerge in pot soil indicating a phytotoxic effect on seed germination (Fig. 3). There was genotype-specific response of storage temperatures on the efficacy of metalaxyl seed treatment on seed germination in the two pearl millet lines. To test this, we conducted a blotter test (details not reported here) wherein metalaxyl-treated seed of $843 \mathrm{~B}$ stored at $40^{\circ} \mathrm{C}$ for 30,60 and 90 days recorded 16,8 and $6 \%$ germination, respectively, compared to 77,77 and $90 \%$ germination in untreated seed stored at the same temperature, while no such adverse effects were recorded for metalaxyl-treated seed of $7042 \mathrm{~S}$ stored at $40^{\circ} \mathrm{C}$ for different time periods.

\section{Discussion}

With the increasing area under pearl millet hybrid cultivation in India, the prevalence and severity of

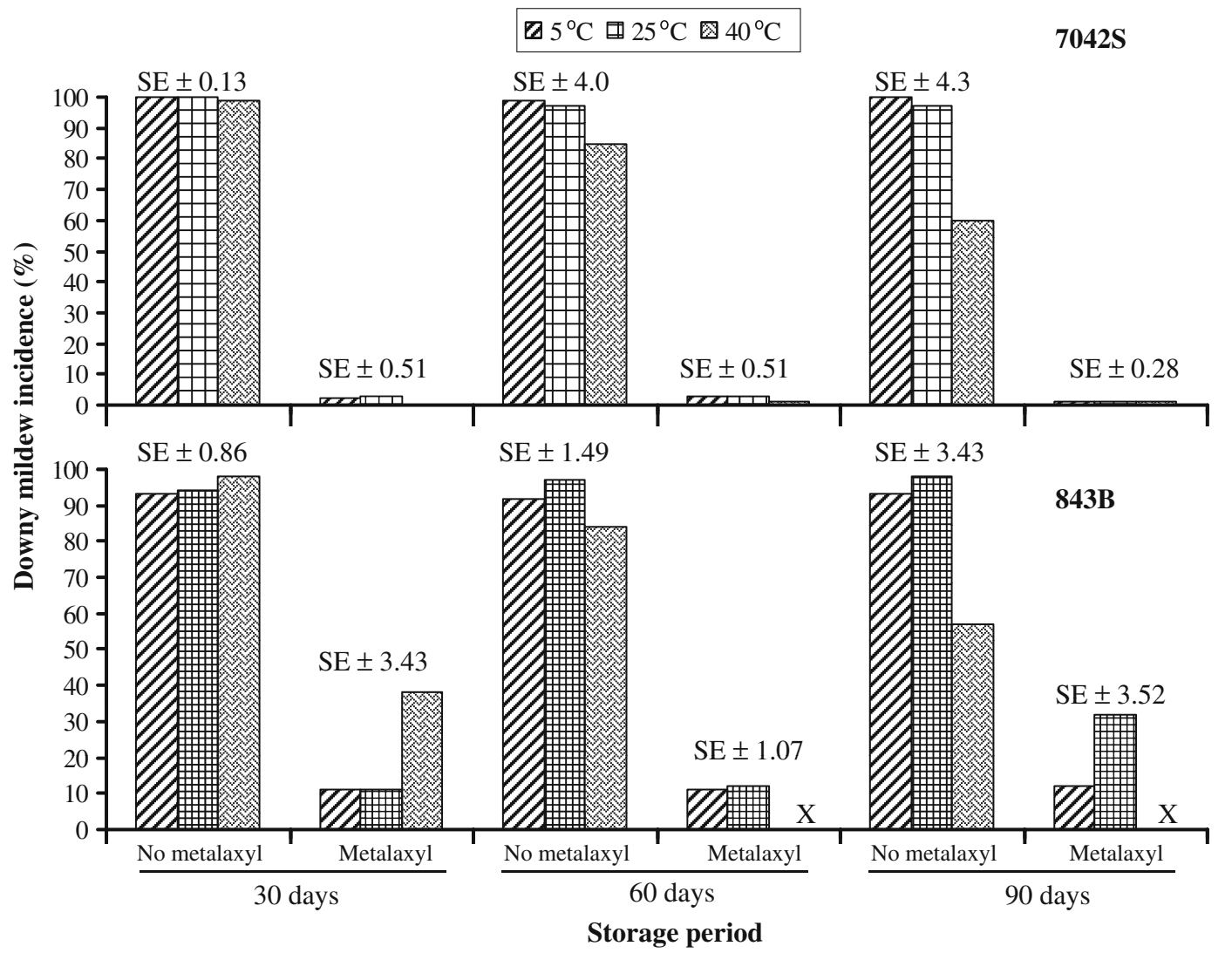

Fig. 3 Effect of storage temperature and duration of metalaxyl (Apron 35WS)-treated seed on downy mildew incidence of two pearl millet lines (7042S and 843B) in a greenhouse experiment.
(Note that metalaxyl-treated seed of $843 \mathrm{~B}$ stored at $40^{\circ} \mathrm{C}$ for 60 or 90 days failed to emerge $(\mathrm{x})$ in pots indicating phytotoxic effect of metalaxyl) 
downy mildew has increased over the years (Thakur et al. 2006). This has necessitated that private seed companies, the major player in promoting and marketing hybrid cultivars, treat the seed with metalaxyl prior to marketing through dealers. In many hybrids where genetic resistance was not adequate they succumbed to the disease even after metalaxyl seed treatment. We have encountered questions frequently from private seed companies regarding reducing the dosages of fungicide, effectiveness of fungicide after seed treatment, and the failure of fungicide to protect the crop from the disease. The results of this study have provided some useful information to the above queries. Reduced dosages of metalaxyl seed treatment in case of moderately resistant lines 7042R and ICMP 451 significantly reduced downy mildew incidence compared to that in the susceptible line $7042 \mathrm{~S}$ (Fig. 1). Reduction in disease incidence was more pronounced even at 60 days in ICMP 451 than in 7042R most likely due to cultivar differences. This information is very useful for the seed companies to effectively and economically protect the crop and increase the commercial life of the hybrid through reduced fungicide dosages.

Metalaxyl-treated seed, under normal field conditions (adequate soil moisture and temperature, and low oospore inoculum load) has been reported to protect the crop from downy mildew only up to 35 days after emergence (Singh and Shetty 1990; Singh 1995). Our results have shown that fungicide protection lasted up to 20 days in the case of a highly susceptible line $7042 \mathrm{~S}$ and up to 50 days in a moderately resistant line ICMP 451 and the disease progress up to 70 days (crop maturity) was much slower in ICMP 451 than in 7042S. Thus fungicide seed treatment in the case of a susceptible cultivar cannot be effective in protecting the crop.

Under tropical climatic conditions, where most pearl millet is grown, proper storage of treated seed is critical. In India, fungicide-treated seed of pearl millet hybrids are stored in small godowns for 2-3 months during hot summer months (April-June) when ambient temperatures reach $45^{\circ} \mathrm{C}\left(48^{\circ} \mathrm{C}\right.$ in tin-shade go-downs) before selling to farmers after the onset of monsoon rains in June-July. Under these conditions, fungicide-treated seed lots are exposed to high temperatures in poorlyventilated small godowns, resulting in reduced seed germination and even making the fungicide ineffective.
Normally, for a fungicide to be effective the seed treatment should be done just before sowing, but that is not the case in India with pearl millet where seed treatment is done by private seed companies and given to dealers 3-4 months ahead of sowing time for selling to farmers. Results of this study have indicated little effect of storage duration and storage temperatures on effectiveness of fungicide seed treatment (Figs. 2 and $3)$; although in one line $(843 \mathrm{~B})$, where fungicidetreated seed was stored at $40^{\circ} \mathrm{C}$ for 60 and 90 days, germination was adversely affected in blotter test and seedling emergence was inhibited in the potting mix. This clearly indicated variable phytotoxic effect of fungicide to different pearl millet lines. From these results, we propose that the long-term strategy of managing downy mildew in pearl millet should integrate the use of a disease-resistant cultivar (Thakur et al. 2008) with judicious use of fungicide seed treatment. This strategy, in addition to providing adequate protection to the crop will help reduce the chances of evolving fungicide-insensitive strains of the pathogen, which has been a major problem with several oomycete pathogens (Gisi and Sierotzki 2008; Thind 2008).

Acknowledgements Critical review and useful comments by our colleague Dr. Suresh Pande is gratefully acknowledged and contribution of Mr. SM Ahmed in refining the figures is appreciated.

\section{References}

CIBA-GEIGY (1989). Technical Product Information-3.

Gisi, U., \& Sierotzki, H. (2008). Fungicide modes of action and resistance in downy mildews. European Journal of Plant Pathology, 122, 157-167.

Hash, C. T., Singh, S. D., Thakur, R. P., \& Talukdar, B. S. (1999). Breeding for disease resistance. In I. S. Khairwal, K. N. Rai, D. J. Andrews, \& G. Harinarayana (Eds.), Pearl millet breeding (pp. 337-379). New Delhi: Oxford \& IBH.

Hash, C. T., \& Witcombe, J. R. (2002). Gene management and breeding for downy mildew resistance. In J. E. Leslie (Ed.), Sorghum and millets diseases (pp. 27-36). Ames: Iowa State Press.

Hess, D. E., Thakur, R. P., Hash, C. T., Sérémé, P., \& Magill, C. W. (2002). Pearl millet downy mildew: Problems and control strategies for a new millennium. In J. E. Leslie (Ed.), Sorghum and millets diseases (pp. 37-42). Ames: Iowa State Press.

Hospital, F., Chevalet, C., \& Mulsant, P. (1992). Using markers in gene introgression breeding programs. Genetics, 132, 1199-1210. 
Khairwal, I. S., Rai, K. N., Yadav, O. P., \& Bhatnagar, S. K. (2004). Pearl millet cultivars. All India Coordinated Pearl Millet Improvement Project, Indian Council of Agricultural Research, Mandor, Jodhpur, India, 22p.

Rai, K. N., Kulkarni, V. N., Thakur, R. P., Houssmann, B. I. G., \& Mgonja, M. A. (2006). Pearl millet hybrid parents research: approaches and achievements. In C. L. L. Gowda, K. N. Rai, Belum V. S. Reddy, \& K. B. Saxena (Eds.), Hybrid parents research at ICRISAT (pp. 11-73). Patancheru, India: International Crops Research Institute for the Semi-Arid Tropics.

Rao, V. P., Kadwani, D. L., Sharma, Y. K., Sharma, R., \& Thakur, R. P. (2007). Prevalence of pearl millet downy mildew, Sclerospora graminicola in Gujarat and pathogenic characterization of its isolates. Indian Journal of Plant Protection, 35, 291-295.

Singh, S. D. (1995). Downy mildew of pearl millet. Plant Disease, 79, 545-550.

Singh, S. D., \& Shetty, H. S. (1990). Efficacy of systemic fungicide metalaxyl for the control of downy mildew (Sclerospora graminicola) of pearl millet (Pennisetum glaucum). Indian Journal of Agricultural Sciences, 60, 575-581.

Singh, S. D., Gopinath, R., Luther, K. D. M., Reddy, P. M., \& Pawar, M. N. (1984). Systemic remissive property of metalaxyl against downy mildew in pearl millet. Plant Disease, 68, 668-670.

Singh, S. D., King, S. B., \& Werder, J. (1993). Downy mildew disease of pearl millet. Information Bulletin no. 37. Patancheru, India: International Crops Research Institute for the Semi-Arid Tropics.
Talukdar, B. S., Khairwal, I. S., \& Singh, R. (1999). Hybrid breeding. In I. S. Khairwal, K. N. Rai, D. J. Andrews, \& G. Harinarayana (Eds.), Pearl millet breeding (pp. 269301). New Delhi: Oxford \& IBH.

Thakur, R. P. (1998). Disease management in pearl millet. In T. S. Thind (Ed.), Diseases of field crops and their management (pp. 53-76). Ludhiana: National Agricultural Technology Information Center.

Thakur, R. P. (2008). Pearl millet. In S. Lodha, R. Mawar, \& B. S. Rathore (Eds.), Disease management in Arid land Crops (pp. 21-41). Jodhpur: Scientific Publishers.

Thakur, R. P., Rao, V. P., Amrutesh, K. N., Shetty, H. S., \& Datar, V. V. (2003). Field surveys of pearl millet downy mildeweffects of hybrids, fungicide and cropping sequence. Journal of Mycology and Plant Pathology, 33, 387-394.

Thakur, R. P., Rao, V. P., Wu, B. M., Subbarao, K. V., Shetty, H. S., Singh, G., et al. (2004). Host resistance stability to downy mildew in pearl millet and pathogenic variability in Sclerospora graminicola. Crop Protection, 23, 901-908.

Thakur, R. P., Shetty, H. S., \& Khairwal, I. S. (2006). Pearl millet downy mildew research in India: progress and perspectives. International Sorghum and Millets Newsletter, 47, 125-130.

Thakur, R. P., Rai, K. N., Khairwal, I. S., \& Mahala, R. S. (2008). Strategy for downy mildew resistance breeding in pearl millet. e-Journal of SAT Agricultural Research, 6 .

Thind, T. S. (2008). Fungicide resistance: a perpetual challenge in disease control. Journal of Mycology and Plant Pathology, 38, 407-418.

Williams, R. J., \& Singh, S. D. (1981). Control of pearl millet downy mildew by seed treatment with metalaxyl. Annals of Applied Biology, 97, 263-268. 